\title{
Arbeidsparticipatie bij Ehlers Danlos Syndroom en Hyper- mobility Spectrum Disorder
}

Katrien Mortelmans

Op 6 juli 2020 behaalde Stijn De Baets ${ }^{1}$ een PhD. in Gezondheidswetenschappen aan de Universiteit van Gent onder supervisie van de promotor Prof. Dr. Dominique Van de Velde en twee copromotoren, Prof. Dr. Patrick Calders en Prof. Dr. Fransiska Malfait. De publieke verdediging Participation in people with the Ehlers-Danlos Syndromes and Hypermobility Spectrum Disorders', gebeurde in volle COVID-19-epidemie helemaal online.

\section{Ehlers-Danlos}

De doelgroep van het onderzoek is strak afgebakend: patiënten met het Ehlers Danlos Syndroom (EDS) en Hypermobility Spectrum Disorder (HSD). Centraal binnen dit proefschrift staat het concept van participatie, gedefinieerd binnen het ICF-raamwerk (figuur 1).

\section{Arbeidsparticipatie}

Hoe participeren EDS en HSD-patiënten aan de samenleving? En, belangrijk voor TBV: wat met hun vermogen om deel te nemen aan arbeid? In deze proefschriftbespreking beperken we ons tot dat deel van het proefschrift dat betrekking heeft op arbeidsparticipatie. Daaruit onthielden we:
1. de gebruikte methodiek van kwalitatief onderzoek;

2. quotes van patiënten waaruit de bevorderende en hinderende factoren voor arbeidsparticipatie afgeleid kunnen worden;

3. een informatief stuk over de steun van de Belgische overheid voor patiënten met beperkingen en

4. de conclusies op basis van 2 en 3 .

\section{De methodiek via diepte-interviews op basis van thematische analyse}

De Baets' kwalitatieve onderzoek probeert op deze vraag antwoorden te vinden door te zoeken naar hinderpalen en bevorderende factoren voor werk.

Deze methode van data-analyse, met als doel de geleefde ervaringen van deelnemers te onderzoeken, bestaat uit zes fasen (tabel 1).

De inclusie van patiënten, datacollectie en -analyse, en resultaten, zijn toegelicht in het Onderzoek in het Kort artikel Arbeidsparticipatie bij Ehlers-Danlos-syndroom. Zie pagina 53 van dit TBV.

Figuur 1. ICF-raamwerk

gezondheidstoestand

aandoeningen, ziekten

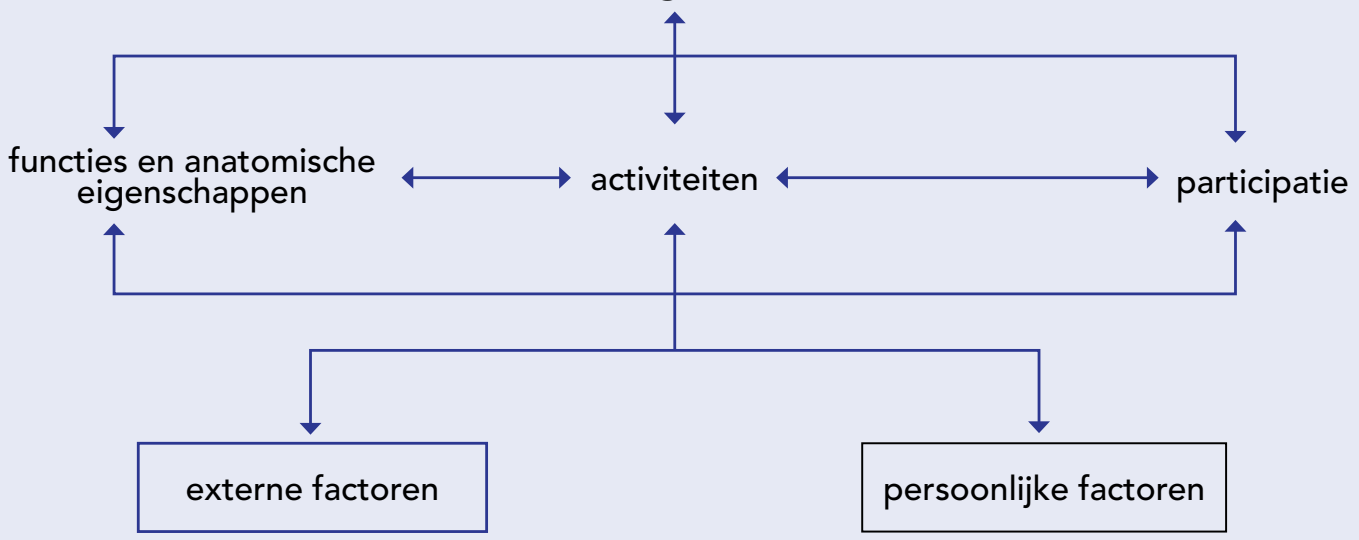


Tabel 1.

De stappen binnen het thematische analyseproces (Braun \& Clarke, 2006) $)^{2}$

\begin{tabular}{|c|c|}
\hline Fase & Beschrijving \\
\hline 1. Vertrouwd raken met de data & $\begin{array}{l}\text { Gegevens transcriberen (indien nodig), } \\
\text { de gegevens lezen en herlezen, eerste } \\
\text { ideeën noteren. }\end{array}$ \\
\hline 2. Initiële codes genereren & $\begin{array}{l}\text { Interessante kenmerken van de gegevens } \\
\text { op een systematische manier coderen } \\
\text { voor de hele gegevensset, waarbij gege- } \\
\text { vens worden verzameld die relevant zijn } \\
\text { voor elke code. }\end{array}$ \\
\hline 3. Thema's zoeken & $\begin{array}{l}\text { Codes verzamelen in mogelijke thema's } \\
\text { en alle gegevens verzamelen die relevant } \\
\text { zijn voor elk potentieel thema. }\end{array}$ \\
\hline 4. Herzien van de thema's & $\begin{array}{l}\text { Nagaan of de thema's werken in relatie } \\
\text { tot de gecodeerde extracten (niveau 1) en } \\
\text { de volledige dataset (niveau 2), waardoor } \\
\text { een thematische 'kaart' van de analyse } \\
\text { wordt gegenereerd. }\end{array}$ \\
\hline $\begin{array}{l}\text { 5. Definiëren en benoemen van } \\
\text { thema's }\end{array}$ & $\begin{array}{l}\text { Voortdurende analyse om de specifieke } \\
\text { kenmerken van elk thema te verfijnen, } \\
\text { en het algemene verhaal dat de analyse } \\
\text { vertelt, waarbij duidelijke definities } \\
\text { en namen voor elk thema worden } \\
\text { gegenereerd. }\end{array}$ \\
\hline 6. Rapportage & $\begin{array}{l}\text { De laatste mogelijkheid voor analyse. } \\
\text { Selectie van levendige, boeiende frag- } \\
\text { mentvoorbeelden, uiteindelijke analyse } \\
\text { van geselecteerde fragmenten, relateren } \\
\text { van de analyse aan de onderzoeksvraag } \\
\text { en literatuur, produceren van een weten- } \\
\text { schappelijk rapport van de analyse. }\end{array}$ \\
\hline
\end{tabular}

2. De ervaringen van patiënten - eigen aan kwalitatief onderzoek - geven een goed beeld van de hinderpalen en bevorderende factoren

"Ik denk dat ik mijn werksituatie moet evalueren. Ik werk drie dagen per week, dit is al erg veeleisend. Ik wil nog steeds wat energie hebben om dingen te doen naast het werk, met mijn familie of vrienden. Tegenwoordig kom ik erg moe thuis van mijn werk en kan ik er niet zijn voor mijn dochter en mijn partner."

"Mijn job wisselde af tussen kantoorwerk en oplevering. Het goede eraan was de variatie in taak en posities, en de mogelijkheid om mijn dag te plannen. (...) Ik zou bijvoorbeeld kunnen besluiten om een uur e-mails te beantwoor den, dan een uur te besteden aan administratieve taken en vervolgens een uur aan iets anders."

"Ik zou nooit zo lang hebben gewerkt als ik niet de flexibiliteit in mijn dienst had gehad. Ik waardeerde het echt dat we onze schema's konden aanpassen. Hoe flexibeler het tijdsschema op het werk is, hoe langer een patiënt kan werken, naar mijn mening."
"Tot nu toe heb ik het gevoel dat ik goed heb kunnen presteren en mijn taken goed heb kunnen uitvoeren. Een van mijn toezichthouders heeft echter al een aantal sterke opmerkingen over mogelijke afwezigheden in de toekomst laten vallen. Hij merkte op dat ik ervoor moest zorgen dat ik niet te veel van de cursussen afwezig zou zijn, omdat continuïteit belangrijk is voor de studenten aan wie ik les geef."

\section{De verwijzing naar de Belgische steunmaatregelen}

De Belgische overheid biedt instrumenten en maatregelen, om de werkgelegenheid van burgers met beperkingen te stimuleren. Voorbeelden zijn 'Gespecialiseerde Trajectbegeleiding ${ }^{3}$ ' of jobcoaching. ${ }^{4}$ Ook konden hun werkgevers eventueel financiële steun ${ }^{5}$ ontvangen.

Uit de bevraging van de patiënten bleek dat die maatregelen ook daadwerkelijk gebruikt werden door de deelnemers. Zo konden meerdere deelnemers weer aan het werk of het werk blijven verder zetten.

\section{De conclusies van het proefschrift inzake arbeidsparticipatie}

a. De geïnterviewde groep hecht belang aan arbeidsparticipatie. Werk brengt voor de studiedeelnemers positieve elementen in het leven, denk maar aan inkomen en sociale relaties.

b. Werken in overeenstemming met de persoonlijke capaciteiten lijkt moeilijk voor deze doelgroep. Een voltijdse werkweek is voor dit soort patiënten vaak een te grote belasting. De mogelijkheid om de werkbelasting af te wisselen draagt bij aan een duurzame inzetbaarheid. Het uitvoeren van taken zoals het tillen van zware voorwerpen of repetitieve handelingen - overschrijdt soms de persoonlijke draagkracht en dit leidt op de lange termijn soms tot het verlaten van de arbeidsmarkt.

c. Het beroepsleven van personen met een beperking, en zo ook voor EDS- en HSD-patiënten, die willen participeren aan het beroepsleven, kan worden ondersteund door overheidsinitiatieven, waardoor rendementsverlies of werkplekaanpassingen kunnen opgevangen worden door financiële tegemoetkomingen.

\section{Referenties}

1. Stijn De Baets: https://www.linkedin.com/in/stijndebaets/

2. Braun V, Clarke V. Using thematic analysis in psychology. Qualitative Research in Psychology. 2006;3(2):77-101. doi: 10.1191/1478088706qp063oa

3. https://www.gtb.be/wat-doet-gtb

4. https://www.vdab.be/werkinzicht/jobcoaching.shtml

5. https://www.vdab.be/arbeidshandicap/wzvop.shtml 